\title{
From Mindfulness to Right Mindfulness: the Intersection of Awareness and Ethics
}

\author{
Mark T. Greenberg • Joy L. Mitra
}

Published online: 13 January 2015

(C) Springer Science+Business Media New York 2015

\section{Introduction}

Monteiro et al. (2015) have raised important concerns regarding the role of ethics in contemporary models of mindfulness interventions. We agree that this is a central and compelling question in the cultural translation of mindfulness and of meditative practice when utilized in Western secular settings. Here, we address some foundational issues relating to the association of mindfulness and secular ethics that we hope will contribute to this discussion. In doing so, we consider mindfulness to be not only a specific set of meditative practices, but also an integral part of the eightfold path in which right speech, right action, right livelihood, etc., are intrinsically linked. Our view involves a broader translation of the term "mindfulness," in accord with that of Bodhi (2011), in which mindfulness necessarily encompasses ethical speech and action as part of a complex set of interrelated processes, which include discernment, discrimination, remembrance, and imagination. This expanded definition moves us from mindfulness toward "right mindfulness" by incorporation of an ethical foundation that may be explicitly taught or implicitly communicated by the embodiment of such values in a teacher.

In this commentary, we do not discuss the second issue raised by Monteiro and colleagues regarding the issue of spiritual materialism, nor their concerns regarding the utilization of meditative techniques in the service of self-advancement, combat, or other more controversial contemporary contexts. However, we share the concerns of the more traditional

M. T. Greenberg $(\bowtie) \cdot$ J. L. Mitra

Prevention Research Center, The Pennsylvania State University, University Park, State College, PA 16802, USA

e-mail: mxg47@psu.edu
Buddhist approach that a delimited approach to mindfulness that does not include an ethical foundation is misappropriated and questionable. We also propose that it may be helpful to begin to articulate principles and criteria to (i) draw a clear line to distinguish mindfulness from right mindfulness in secular interventions and (ii) serve as scaffolding for development of an ethical framework.

\section{Association of the Desire for Happiness with the Intention to End Suffering}

Historically, ethical practices have often been directly bound to one's faith or religious perspective. There are common elements to most of the world's spiritual practices (Judeo-Christian, Buddhist, Islamic, Religious Society of Friends, etc.). In each of these traditions, there are at least three elements: practices, ethical beliefs/teachings, and community building. The first element, practices, can include prayer, pilgrimage, ritual, meditative techniques, witnessing, and many other practices (see the Tree of Contemplative Practices http://www.contemplativemind. org/practices/tree as one model). Second, there is typically a set of ethical principles or precepts that are delivered in the form of oral sermons, homilies, dharma talks, as well as through prayers, songs, and actions. Further, in all different spiritual traditions, followers look towards their leaders (priests, rabbis, guru, master) for the everyday embodiment of these principles. Third, these perspectives and principles are traditionally "held" by a like-minded group that supports the group's norms and reinforces their beliefs. This "formula" of practices, beliefs/ethical teachings, and a community that "holds" these practices and teachings is central to spiritual 
traditions throughout history and appears to reflect some commonly held tendencies of human nature (Fig. 1).

In responding to the typical association in Western psychology between positive and negative emotions, those that result in pleasure and pain, H. H. the Dalai Lama (2011) asserted that a primary distinction in Buddhist psychology is between those states that are beneficial and those that are harmful. When examining human intention and motivation, we agree with Flanagan (2003) that it is important to go beyond a utilitarian focus on pleasure for the many (especially if secured at the expense of increased suffering for the few) and to contextualize wholesome actions not only as personal, but as interpersonal and social in nature. If the association of the human tendency to seek happiness with the normative goal of achieving what is beneficial is assumed to be a determinant of moral/ethical beliefs across cultures and belief systems, then the secular basis for the intention to reduce suffering is a universal motivation experienced at the species level and honored across cultures.

\section{Expanding the Contexts of Mindfulness: From Being to Discerning}

The "contemporary" definition of mindfulness, as nonjudgmental awareness in the present moment, is a secularization of one interpretation of the traditional concept of Sati, but this definition limits or asseverates bare awareness from related practices traditionally connected with mindfulness as "the guarantor of correct practice of all the other path factors" (Bodhi 2011, p. 26). An expanded definition necessarily enlists the engagement of other essential and universal human faculties, such as memory, discernment, reason, and imagination. Bodhi (2011) argued that "the practitioner of mindfulness must at times evaluate the mental qualities and

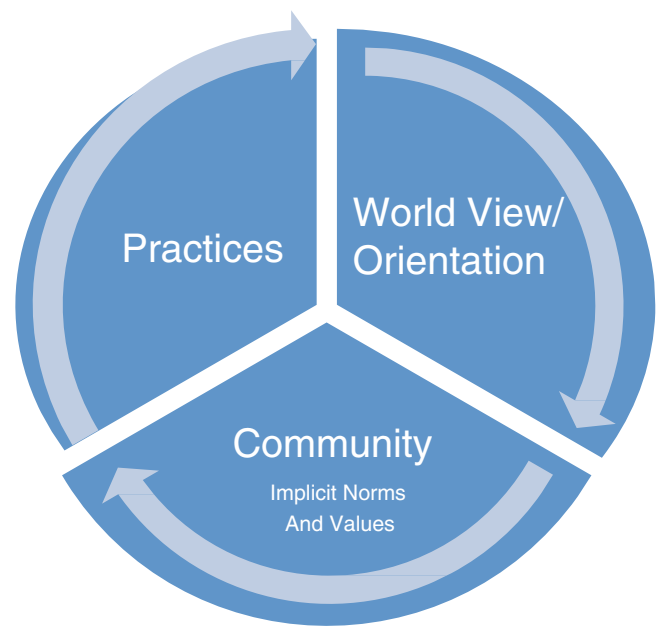

Fig. 1 Common elements of spiritual practices intended deeds, make judgments about them and engage in purposeful actions" (p. 26). Similarly, Grossman and Van Dam (2011) argued that "attention and awareness are at most aspects that serve as preconditions, rather than equivalents of mindfulness" (p. 223), and Dreyfus (2011) emphasized the evaluative aspects of mindfulness that distinguish wholesome from unwholesome states.

Bodhi (2011) argued that if mindfulness is to qualify as right mindfulness, it must be connected to a "web of factors that give it direction and purpose" (p. 26). When mindfulness is situated as a part of this broader scaffolding, it serves the transitive function not only of relating subject to object but also to the dynamic web of interconnectedness of all subjects; in this way, mindfulness enables a natural progression from the release of suffering at an individual level to larger scale transformation at the interpersonal and collective level of engaged teaching, learning, and ethical action. Although personal aspects of mindfulness (meditative practices as well as dharma) can be appreciated without a group context, it is only in some rare modern conditions (such as learning over the Internet, by audiotapes, or as an adjunct to some forms of psychotherapy) that this would happen. Most contemporary models of mindfulness instruction also involve a group context, albeit not necessarily the construction of an ongoing community. A definition of the practice of right mindfulness is thus premised on a clear intention to generate well-being at both the individual and at the universal, species-wide level.

\section{Considerations for Constructing a Curriculum for Right Mindfulness}

We also agree that contemporary mindfulness approaches that do not directly address ethics are "incomplete"; that is, a sole focus on the cultivation of concentration and attention is an inadequate curriculum for living a mindful existence or for the construction of interpersonal or organizational interventions aimed at reducing suffering or eliminating inequity. At the level of cognition, this broader view of mindfulness reflects movement from attention and awareness through the related mental factors of discernment, intention, imagination, and reason toward the ends of developing wise understanding and engendering beneficial or wholesome outcomes.

This view is supported in many traditions, in which mindfulness is considered to be a preparatory activity, first for meditation and concentration, and successively from that point to the causal unfolding of the steps on the eightfold path. Monteiro et al. (2015) argued that the categories of the eightfold path "are descriptions of capacities or potentials shared by all human beings" (p. 3). When Thupten Jinpa 
(2014) expressed concern about Buddhism being "reduced to just meditation" and meditation being "reduced to just mindfulness," he was calling attention to the potential problems associated with decontextualizing the practice of mindfulness from its original context.

Referencing the continuity of interrelated mental factors provides us with a basis for encountering and overcoming obstacles or hindrances, such as attachment, ignorance, and destructive emotions. Wallace and Bodhi's (2006) view was that the state of pure mindfulness cannot coexist with the presence of hindrances, because the junction of sati and panna (the "wisdom that penetrates the true characteristics of phenomena") results in transcendence beyond the separate self, the root of all cravings and attachments. When considered in the context of the interpersonal sphere of social action, the steps of the eightfold path direct awareness forward to the plane of ethical action. In interventions involving the broader community, such as those with families, teachers, and youth, the extension of mindfulness to right speech and right action is critically important when developing a curriculum for mindfulness.

With this goal in mind, it is important to remind ourselves that induction into the Buddhist cannon is not necessary for understanding the Four Noble Truths (including the nature of suffering and how to relieve it). As Monteiro et al. (2015) noted, "Kabat-Zinn points out that it is not necessary to evoke the Buddhist model of liberation in order to convey the concepts that underpin it" (p. 7). Aside from teachings that are specifically Buddhist, the unfolding of the eightfold path occurs in a natural, causal progression, reflecting the intricate and essential connections between human cognition and behavior. Consequently, action, speech, livelihood, and other path elements, when practiced without an ethical frame, can and do lead to suffering.

In taking a mindful approach to both noticing and detaching from destructive emotions, such as anger, hatred, and greed, we recognize them as forms of ego-clinging and as distortions of the actual experience at hand (Ricard 2003). By following this path at the cognitive level, we begin to discern the causes of suffering as set forth in the Second Noble Truth. When understanding is modulated by motivation and intentionality, it can generate the potential for overcoming these obstacles through the practice of right speech, right action, and right livelihood.

One methodological question here is whether this progression is merely an emergent aspect of practice or whether it requires conscious cultivation. Bodhi (2011) argued that immediate perceptual apprehension is ethically neutral, but that "mindfulness does not occur automatically; it is a quality to be cultivated" (p. 28). The current debate suggests that one cannot unreservedly assume the former view of emergence; i.e., instruction in the regular practice of meditation may not alone be sufficient.

\section{The "What is" and the "What Can Be"}

Many commentators have expressed the concern that, by emphasizing nonjudgmental awareness, we may be cultivating a consciousness that renders samsara more palatable, rather than working from a cohesive theory and practice of liberation from samsara with all its mental afflictions (Wallace and Bodhi 2006). Preparation of interventions directed at the liberation of sentient beings necessarily involves encounters with conflict, incorporation of systematic learning, and engagement in many-sided debates. Such activities result in the extension of the awareness of individual experience to intentional actions that generate well-being at the interpersonal or collective level. Recognition of the nature of hindrances or obstacles on the path supports inclusion of practices such as those that involve taking the perspective of the other, e.g., loving-kindness and tonglen (Tibetan for "giving and receiving"). In incorporating the "concepts that underpin" these other-directed practices (Monteiro et al. 2015, p. 7), we expand the intention, understanding, and view of the subject to include the awareness and suffering of the other, or, as in tonglen, to exchange one's own happiness for the suffering of the other.

\section{Foundational Principles of Secular Ethics}

Here, we are searching for a basis for a species-wide articulation of a secular ethics that can serve as an implicit or explicit guide for the practice of right mindfulness. One purpose of the practice of nonjudgmental, present-moment awareness is to enable us to disengage from the conceptual attachments, discursive scripts, and automatic reactions that are at the root of suffering. Not only does this grounding in present-moment awareness yield clarity of vision, but it can also serve as the "nutriment" for emergent intentionality and discernment, linking insight with the skillful practices of right speech and actions (Wallace and Bodhi 2006). Some foundational principles that can support such a proposed ethical frame are (i) nonharming (ahimsa), as in the Hippocratic Oath; (ii) interdependence, as increasingly manifested across all fields of natural and social sciences, e.g., quantum theory, ecological environmental theories, economic globalization, social media, and planetary tools for reducing egotism (Scharmer and Kaufer 2013); and (iii) the Golden Rule, one way of expressing the crux of various formulations of virtuous action.

In other words, the push toward universal and speciesfriendly principles of ethics requires inclusion of a normative component in the practice of mindfulness in the arenas of speech and action. This suggests a possible bright-line test for differentiating contemporary notions of mindfulness (sati) from the practice of right mindfulness (samma sati). By this, we mean that if a reduction in suffering for an individual 
results in increased suffering for the community, whether or not as a result of conscious intention, then such practice cannot be considered as right mindfulness. Without this extension into ethical actions, our good intentions and focused energies may result in cultivating miccha sati. It would therefore be interesting to test these foundational principles through programs incorporating implicit and explicit ethical frames that can then be evaluated for both qualitative and quantitative outcomes.

\section{Derivation of Right Action and Right Speech from Recognition of Interdependence}

The path from awareness via intentionality to right action and right speech is conditioned upon the recognition of interdependence. Of course, when evaluating contexts for right mindfulness, if we define the community in a universal manner to include all living beingsnot just the members of one classroom, nor of a single corporation, nation-state or sect-then we can generalize the practice of mindfulness to align with the wisdom of the Third Noble Truth.

In this review, the embodiment of a broad and inclusive ethical framework is suggested as an alternative approach to methods that fail to invoke the fundamental principle of interdependence as an essential element on the path to wellbeing. Just as mindfulness is intended to secularize the practice of meditation, this consideration of the conceptual elements of the eightfold path is intended to serve as a platform for development of a secular ethical frame operative at the species level.

The current MBSR definition of mindfulness neither permits critique or debate of what is unjust nor expands our outlook to what may be. Insofar as it is applied within clinical settings by professionals bound by the Hippocratic Oath, there can be a reasonable assumption of convergence. When our practices enter social and interpersonal spheres not governed by adherence to explicit ethical codes, we see greater risk.

It is not our contention that we should be seeking to "fix" something, but rather to set in motion a tendency and urgency to move toward the greater good using nonsectarian ethical principles and wise discernment. Contemporary practices that invoke a prohibition against wanting things to be other than they are - that limit the role of remembrance, discernment, and intentionality - may restrict us to a mode of unquestioning acceptance of whatever oppressive forms are dominant in the present moment (Wallace and Bodhi 2006). Without a clear commitment to alleviating individual suffering in a manner that does not increase suffering for others, might we be reinforcing passivity and maintaining oppression for teachers, students, and others?

\section{Dialectics of Right Mindfulness: What is Not and What May Be}

Thus, we are in agreement with a model for mindfulness interventions that either implicitly or explicitly recognizes the importance of both presenting and living within an ethical framework and which, in either case, recognizes moral/ethical values as a necessary component in the practice of right mindfulness. In the case where an explicit ethical code is incorporated in a mindfulness intervention, it should be clearly articulated. In the case of an implicit moral code, the training of mindfulness teachers should be clear and directed toward wholesome ends (beneficial outcomes) as well as skillful means. In the CARE for Teachers program, this is accomplished with teachers in a nonprescriptive manner by asking them to set and use their own intentions as a personal compass, to develop a statement of the values that motivated them to become teachers, and to utilize these values in their actions with others (Jennings et al. 2011, 2013).

Mindfulness is often defined by what is not — by not doing, not judging, not striving, and not imagining. In contemporary mindfulness programs, the emphasis on non-striving and nonjudging is considered an essential grounding for achieving clarity of mind and release from harmful emotions and thoughts. Wallace and Bodhi (2006) argued, however, that this property of Sati also enabled it to serve as "the charioteer" that connects various mental states, conducting them with clarity towards the object. So in the progression from mindful awareness through discernment and skillful action, the dialectical progression from "what is not" is completed, in samma sati, by discerning not only the "what is" but the "what could be" and also the "what is beneficial." In other words, at the level of relative truth and everyday experience, the subject is then completed with a predicate - with an intentional disposition toward the object of discernment and toward the goal of ending suffering. Such intentions must of course be directed toward opening the broad common grounds of non-sectarian, universal ethics that are species-wide in scope.

\section{Imagining the Future}

Especially in mindfulness interventions with families, teachers, and youth in classrooms and community centers, we have the opportunity to reach beyond our individual finite existences to help direct the chain of cause and effect toward beneficial outcomes that transcend the limits of our own present condition. With that in mind, we offer some preliminary thoughts about possible secular grounds and practices that may contribute to developing a common ethical framework for mindfulness interventions: (i) discernment exercises that extend the "what is" to "what is beneficial" when developing human capacity; (ii) creation of a learning or 
developmental space to encourage inquiry into and critical evaluation of the causes of suffering; (iii) skillful examination of the grounds of human motivations and intentions; (iv) cultivation of respect for serious study and learning essential to development on the path of wisdom; (v) removing the hindrances and obstacles to safe, healthy, and democratic modes for organizing human communities; (vi) including exercises to foster taking the perspective of the other; (vii) leading with the premise that people are more alike than different, yet mindfully exploring, recognizing and honoring differences; (viii) cultivating nonaggression and peaceful modes of action, (ix) developing mutual tolerance and respect for all faiths; and (x) watering the seeds of compassion.

The linkage of inner and outer values, which results in intentional actions directed toward the highest good, is a common factor that unites many faith traditions. In this argument for the development of criteria for secular ethics, the central normative affirmation must be that actions result in well-being for both the self and for others - neither being sufficient on its own. As such, we believe that it is possible to outline a framework of broad criteria that are neither moralistic nor sectarian. Careful development of these criteria is essential in order to move from a well-developed emphasis on mindfulness to one of right mindfulness.

\section{Conclusion}

As educators, we suggest and evoke the future in our words and in our actions. Undoubtedly both teachers and parents play a critical role in unlocking capacities of youth - capacities that can result not only in reducing suffering, but also in releasing the fruits of human potential in ways that go beyond what we, as individuals, can now imagine. The current debate is an opportunity to connect our shared sense of urgency for unlocking human capacity with the temperate and systematic articulation of ethical principles. If successful, this fusion of sati and sila can bear fruit in a curriculum of right mindfulness - in a manner that is tested, evidence-based and scientific - but that points inevitably toward the end of suffering.

\section{References}

Bodhi, B. (2011). What does mindfulness really mean? Contemporary Buddhism, 12(1), 19-39.

Dalai Lama, H. H. (2011). Beyond religion: Ethics for a whole world. Boston: Houghton Mifflin Harcourt.

Dreyfus, G. (2011). Is mindfulness present-centered and non-judgmental? A discussion of the cognitive dimensions of mindfulness. Contemporary Buddhism, 12(1), 41-54.

Flanagan, O. (2003). The Western perspective. In D. Goleman (Ed.), Destructive emotions: How can we overcome them? A scientific dialogue with the Dalai Lama. New York: Bantam.

Grossman, P., \& Van Dam, N. (2011). Mindfulness, by any other name...: trials and tribulations of sati in Western psychology and science. Contemporary Buddhism, 12(1), 219-239.

Jennings, P., Snowberg, K., Coccia, M., \& Greenberg, M. (2011). Improving classroom learning environments by cultivating awareness and resilience in education (CARE): results of two pilot studies. Journal of Classroom Interaction, 46(1), 37-48.

Jennings, P. A., Snowber, K. E., Frank, J. L., Coccia, M. A., \& Greenberg, M. T. (2013). Improving classroom learning environments by cultivating awareness and resilience in education (CARE): results of a randomized controlled trial. School Psychology Quarterly, 28, 374 390.

Jinpa, T. (2014). Under one umbrella: can tradition and science both fit? An interview with Thupten Jinpa. Retrieved from http://www. tricycle.com/feature/under-one-umbrella.

Monteiro, L., Musten, R., \& Compson, J. (2015). Traditional and contemporary mindfulness: finding the middle path in the tangle of concerns. Mindfulness, 6, 1-13. doi:10.1007/s12671-014-0301-7.

Ricard, M. (2003). A Buddhist psychology. In D. Goleman (Ed.), Destructive emotions: How can we overcome them? A scientific dialogue with the Dalai Lama. New York: Bantam.

Scharmer, O., \& Kaufer, K. (2013). Leading from the emerging future: From ego-system to Eco-system economies. San Francisco: BerrettKoehler Publisher.

Wallace, B., \& Bodhi, B. (2006). The nature of mindfulness and its role in Buddhist meditation. A correspondence between B. Alan Wallace and Bhikkhu Bodhi. Retrieved from http://shamatha.org/sites/ default/files/Bhikkhu_Bodhi_Correspondence.pdf. 